\title{
Erratum to: Polymer-Grafted Nanographite Support Obtained Using Iminodiacetic Acid/Allyl Glycidyl Ether: Characterization and Application in the Extraction and Determination of Enrofloxacin in Biological and Pharmaceutical Samples
}

\author{
Atefeh Alimadadi ${ }^{1,2} \cdot$ Homayon Ahmad Panahi ${ }^{2} \cdot$ Faramarz Afshar Taromi $^{1}$. \\ Elham Moniri ${ }^{3}$
}

Published online: 11 February 2016

(C) Springer-Verlag Berlin Heidelberg 2016

\section{Erratum to: Chromatographia}

DOI 10.1007/s10337-015-2990-z

The authors should like to call the readers' attention to the fact that the list of authors and affiliations have been expanded as:

Atefeh Alimadadi ${ }^{1,2}$, Homayon Ahmad Panahi ${ }^{2, \text {, }}$,

Faramarz Afshar Taromi ${ }^{1}$, Elham Moniri ${ }^{3}$

${ }^{1}$ Department of Polymer Engineering,

Amir Kabir University of Technology, Tehran, Iran

${ }^{2}$ Department of Chemistry, Central Tehran Branch, Islamic Azad University, Tehran, Iran

${ }^{3}$ Department of Chemistry, Varamin (Pishva) Branch, Islamic Azad University, Varamin, Iran

$\bowtie$ h.ahmadpanahi@iauctb.ac.ir

The online version of the original article can be found under doi:10.1007/s10337-015-2990-z.

Homayon Ahmad Panahi

h.ahmadpanahi@iauctb.ac.ir

1 Department of Polymer Engineering,

Amir Kabir University of Technology, Tehran, Iran

2 Department of Chemistry, Central Tehran Branch, Islamic Azad University, Tehran, Iran

3 Department of Chemistry, Varamin (Pishva) Branch, Islamic Azad University, Varamin, Iran 